secondary IFTC conjugated antibodies; and 2) in SDS-PAGE electrophoresis and blotting using the corresponding antibodies. Results Fluorescence inmunohistochemically shows specific extracellular expression of biglycan and decorin in chondrocytes cultured in estandard $[\mathrm{Na}+](154 \mathrm{~nm})$ and western blotting intensities of these small proteoglycans varied with $[\mathrm{Na}+]$.

Conclusion This study demostrates that biglycan and decorin are expressed in the human chondrocyte cell line C20A4. We are now searching if $[\mathrm{Na}+]$ variations is able to produce cualitative or cuantitative alterations in the matrix synthesis as it have been found in osteoarthritis.

-Supported by FIS grant 99/0695-

\section{AB0020 COMPARISON OF SYNOVIAL MMP-1 AND TIMP-1 LEVELS IN PATIENTS WITH VARIOUS INFLAMMATORY ARTHRITIDES}

S Pay, H Erdem, M Serdar, A Dinc, I Simsek, M Turan. Department of Internal Medicine Division of Rheumatology, Department of Hydroclimatology and Medical Ecology, and Department of Biochemistry, Gülhane School of Medicine, Ankara, Turkey

\subsection{6/annrheumdis-2001.914}

Background Some inflammatory arthritides like a rheumatoid arthritis cause erosion in bones and destruction in cartilage, but others such as Behçet's Disease (BD) and Familial Mediterranean Fever (FMF) do not.

Objectives The purpose of this study was to investigate synovial levels of matrix metalloproteinase ?1 (MMP-1) known to break collagen, and tissue inhibitor of metalloproteinase (TIMP-1), its natural antagonist, in patients with various inflammatory disorders.

Methods One hundred and nine patients with different inflammatory arthritides were enrolled in the study (20 BD, $20 \mathrm{FMF}$, 24 spondyloarthropathy (SPA), 26 rheumatoid arthritis (RA) and 19 osteoarthritis (OA)). All patients had at least one-sided knee arthritis from which synovial fluid samples were obtained. Patients with BD, FMF and SPA constituted three study groups. Patients with RA and OA were used as control groups. Synovial MMP-1 and TIMP-1 levels were measured by two-step sandwich ELISA.

Results The mean levels of synovial MMP-1 and TIMP-1 of the study and control groups presented in Table 1.

\begin{tabular}{lllllll}
\multicolumn{6}{l}{ Abstract AB0020 } & Table 1 \\
\hline & BD & $\begin{array}{l}\text { Study Groups } \\
\text { FMF }\end{array}$ & SPA & $\begin{array}{l}\text { Control } \\
\text { RA }\end{array}$ & $\begin{array}{l}\text { Groups } \\
\text { OA }\end{array}$ & $\mathbf{p}^{*}$ \\
\hline MMP-1 & $0.305 \pm$ & $0.237 \pm 0.253$ & $0.190 \pm$ & $0.244 \pm$ & $0.126 \pm$ & 0.019 \\
mcg/dl & 0.217 & & 0.224 & 0.230 & 0.113 & \\
TIMP-1 & $6.040 \pm$ & $5.784 \pm 3.378$ & $6.080 \pm$ & $5.660 \pm$ & $8.574 \pm$ & 0.017 \\
mcg/dl & 2.490 & & 3.960 & 2.931 & 2.702 & \\
\hline MMP-1 and TIMP-1 levels of the study and control groups (*Kruskal-Wallis test).
\end{tabular}

Conclusion Although FMF and BD are generally characterised by nonerosive arthritis, our results showed that synovial MMP-1 levels of patients with BD and FMF were not different from the patients with RA, which is a well-known erosive arthritis. We suggested two possible explanations for these unexpected data. First, BD and FMF generally cause short term arthritic attacks, remitting without permanent damage. Second, high synovial MMP-1 levels in BD and FMF may be resulted from extra articular origin, because of their systemic nature. The comparison of synovial MMP-1 levels between RA and SPA was statistically significant. This may help to explain why SPA causes less prominent destruction in cartilages and erosion in bones than RA. Except OA, the difference between the groups with respect to the synovial TIMP-1 levels was statistically insignificant.

\section{AB0021 TOPIRAMATE AS SUSPICIOUS CAUSE OF ARTHROPATHY- ANOTHER CASE REPORT}

${ }^{1} \mathrm{G}$ Saviola, ${ }^{1} \mathrm{~L}$ Abdi Ali, ${ }^{2} \mathrm{~S}$ Avanzi, ${ }^{3} \mathrm{M}$ Castagna, ${ }^{4} \mathrm{D}$ Idone. ${ }^{1}$ Rheumatology Unit, Salvatore Maugeri Foundation IRCCS, Castel Goffredo, Mantua; ${ }^{2}$ Neuropsichology Unit; ${ }^{3}$ Rehabilitation Department; ${ }^{4}$ Department of Neurology, Pederzoli Hospital, Peschiera Del Garda, Verona, Italy

10.1136/annrheumdis-2001.915

Background One year ago we described the case of a 23 year old female suffering from idiopathic generalised epilepsy treated with valproate and topiramate. The patient developed a poliarthritis that improved after topiramate was discontinued. ${ }^{1}$

Objectives

Methods We present a 58 year old male suffering since 1996 from epileptic seizures and left hemiplegia secondary to subharachnoid haemorrhage; he had a history of hypertension, diabetes and cigarette smoke.

Results Since September 1999 the patient was treated with phenobarbital at the dose of $100 \mathrm{mg}$ per day, since January 2000 topiramate was added at the dose of $100 \mathrm{mg}$ per day. He was admitted in our department in July 2000 because of worsening of the motor performance: due to myalgias of the limbs, arthralgyas to the left knee and hand, and a frozen left shoulder (it was impossible to obtain any passive movement of that joint). X-ray of the left shoulder showed Sudeck?s atrophy; rheumatological blood tests were negative. We stopped topiramate and substituted it with gabapentin at the dose of $100 \mathrm{mg}$ t.i.d.. 3 months after suspension of topiramate, continuing the treatment with gabapentin and phenobarbital, the patient showed a marked improvement in the range of motion of the left shoulder (passive abduction of $45^{\circ}$; because of hemiplegia, active movements were impossible); moreover arthralgyas and myalgias at the limbs disappeared.

Conclusion Topiramate, a new anti-epileptic drug, seems to have a potential arthropathic role which should be better studied.

\section{REFERENCE}

1 Saviola G, Abdi Ali L, Avanzi S, Idone D. Poliartrite da Topiramato: caso clinic. Reumatismo 2000;52(3):627

\section{THU0052 FIBROBLAST-LIKE SYNOVIOCYTES FROM RHEUMATOID ARTHRITIS PATIENTS ARE MORE INVASIVE THAN FROM OSTEOARTHRITIS IN AN IN VITRO SYSTEM: CORRELATION WITH GROWTH CHARACTERISTICS AND EXPRESSION OF MMP-1, MMP-3 AND MMP-10}

TC Tolboom¹, E Pieterman'1 WH Vd Laan², AL Huidekoper ${ }^{1}$, RG Nelissen ${ }^{3}$, FC Breedveld ${ }^{1}$, TW Huizinga'. 'Rheumatology; ' ${ }^{2}$ Gaubius Laboratory, TNO Prevention and Health, Leiden, The Netherlands; ${ }^{3}$ Orthopaedic Surgery

10.1136/annrheumdis-2001.916

Background

Objectives Fibroblast-like synoviocytes (FLS) are involved in joint destruction. In this study the invasiveness in a transwell 